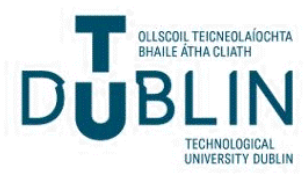

Technological University Dublin

ARROW@TU Dublin

2014-02-12

\section{In-package Nonthermal Plasma Degradation of Pesticides on Fresh Produce}

\author{
N. Misra \\ Technological University Dublin, misra.nrusimhanath@tudublin.ie \\ Shashi Pankaj \\ Technological University Dublin, shashi.pankaj@tudublin.ie \\ Tony Walsh
}

See next page for additional authors

Follow this and additional works at: https://arrow.tudublin.ie/schfsehart

Part of the Atomic, Molecular and Optical Physics Commons, Food Chemistry Commons, Food Processing Commons, Other Chemical Engineering Commons, and the Plasma and Beam Physics Commons

\section{Recommended Citation}

Misra, N. N., Pankaj, S. K., Walsh, T., O’Regan, F., Bourke, P., \& Cullen, P. J. In-package nonthermal plasma degradation of pesticides on fresh produce. Journal of Hazardous Materials, in-press, http://dx.doi.org/ 10.1016/j.jhazmat.2014.02.005

This Article is brought to you for free and open access by the School of Food Science and Environmental Health at ARROW@TU Dublin. It has been accepted for inclusion in Articles by an authorized administrator of ARROW@TU

Dublin. For more information, please contact

arrow.admin@tudublin.ie, aisling.coyne@tudublin.ie, gerard.connolly@tudublin.ie.

Funder: Irish Research Council

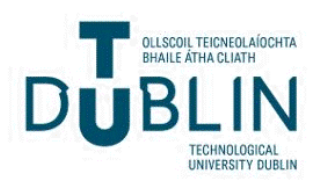




\section{Authors}

N. Misra, Shashi Pankaj, Tony Walsh, Finbarr O'Regan, Paula Bourke, and Patrick Cullen

This article is available at ARROW@TU Dublin: https://arrow.tudublin.ie/schfsehart/136 


\title{
In-package nonthermal plasma degradation of pesticides on fresh produce
}

\author{
N.N. Misra ${ }^{1,+}$, S.K. Pankaj ${ }^{1}$, Tony Walsh ${ }^{2}$, Finbarr O’Regan ${ }^{2}$, Paula Bourke ${ }^{1}$, P.J. Cullen ${ }^{1,3, *}$ \\ ${ }^{1}$ BioPlasma Research Group, School of Food Science and Environmental Health, Dublin Institute of \\ Technology, Dublin 1, Ireland \\ ${ }^{2}$ National Pesticide Laboratory, The State Laboratory, Department of Agriculture, Food and the \\ Marine, Backweston Laboratory Campus, Celbridge, Kildare, Ireland \\ ${ }^{3}$ School of Chemical Engineering, University of New South Wales, Sydney, Australia. \\ *P.J. Cullen; Tel (凅): +353 1402 7595; E-Mail: pjcullen@dit.ie \\ † N.N. Misra; (凅): +353 1402 4367; E-Mail: misra.cftri@gmail.com; misra.nrusimhanath@dit.ie \\ Keywords: nonthermal plasma, dielectric barrier discharge, pesticide, GC-MS/MS
}

\section{Abstract}

In-package nonthermal plasma (NTP) technology is a novel technology for the decontamination of foods and biological materials. This study presents the first report on the potential of the technology for the degradation of pesticide residues. A cocktail of pesticides, namely Azoxystrobin, Cyprodinil, Fludioxonil and Pyriproxyfen was tested on strawberries. The concentrations of these pesticides were monitored in priori and post- plasma treatment using GC-MS/MS. An applied voltage and time dependent degradation of the pesticides was observed for treatment voltages of 60,70 and $80 \mathrm{kV}$ and treatment durations ranging from 1 to $5 \mathrm{~min}$, followed by $24 \mathrm{~h}$ in-pack storage. The electrical characterisation revealed the operation of the discharge in a stable filamentary regime. The discharge was found to generate reactive oxygen and excited nitrogen species as observed by optical emission spectroscopy. 


\section{Introduction}

The use of pesticides in modern agricultural practices has enabled the stabilisation of crop production patterns globally. Nevertheless, the environmental and health problems associated with the use of pesticides at such a global scale cannot be overlooked. A constant search for new pesticides is on-going to combat the resistance developed by pests against traditional pesticides. For example, fungicides, such as azoxystrobin, cyprodinil, fludioxonil and pyriproxyfen are relatively new pesticides that have been introduced into the marketplace [1]. However, the fact that agricultural products cannot be sold if they contain pesticides exceeding the residual limit implicates the need for development of methods to effectively eliminate residual pesticides in harvested crops [2, 3].

For the past two decades, research in food science has largely focused on nonthermal technologies such as high pressure, pulsed electric field, ultrasound, pulsed light, and ozone processing technologies. Nonthermal plasma (NTP) is a relatively novel technology for the decontamination of fresh foods and food processing surfaces. NTP is widely used at an industrial scale for material processing $[4,5]$. The fundamentals of NTP and its applications to decontamination of foods were reviewed by Misra, Tiwari, Raghavarao and Cullen [6] and Niemira [7]. Unlike microbiological decontamination, only a limited number of studies have demonstrated the successful degradation of pesticides by NTP. The degradation of Dichlorvos and Omethoate organophosphorus pesticides sprayed onto maize samples when treated with an inductively coupled radiofrequency NTP source operating in oxygen was studied by Bai, Chen, Mu, Zhang and Li [8]. Recently, Bai, Chen, Yang, Guo and Zhang [9] also demonstrated the successful degradation of dichlorvos pesticides coated on glass slides using the same inductively coupled plasma (ICP) source. In an earlier study, Kim, Kim and Kang [10] reported the decomposition of paraoxon and parathion with an atmospheric pressure, radio-frequency plasma generated in $\mathrm{Ar}$ and $\mathrm{Ar} / \mathrm{O}_{2}$ mixture. However, to the best of our knowledge there have been no studies regarding NTP aided pesticide degradation on fruits and vegetables, in general, and strawberries in particular.

In-package nonthermal plasma is a novel and highly desirable technology for food and bio-decontamination [11]. It involves generation of a NTP inside a sealed package containing the food or biomaterial intended for treatment. The reactive species generated by plasma persist up to a few hours inside the packaging, during which time there is a significant antimicrobial effect. Critically the generated short life active species revert back to the original gas [12]. We have successfully demonstrated the ability of DBD based in-package NTP in air to inactivate background microflora on strawberries, without inducing significant changes in quality [13]. Recently, our group also demonstrated the inactivation of an enzyme in tomato extract using the same plasma source [14]. We have not found significant changes in the food packaging material following NTP treatments to declare hazards from this process $[15,16]$. Besides microbiological concerns, pesticides residues in strawberries also pose a serious health risk, for they are often consumed without washing or are minimally processed. This work investigates the potential of in-package NTP for the degradation of pesticide residues on strawberries.

The aims of the present study were to find out if in-package NTP can degrade pesticide residues on strawberries. More specifically, the study involves quantifying the degradation of fungicides, namely azoxystrobin, cyprodinil, fludioxonil, and pyriproxyfen on strawberry surface by GC-MS/MS analysis, under the influence of NTP treatment. A brief summary of these pesticides, including chemical structure, toxicity is provided in Table 1. With an aim to explain the observed effects, the electrical and optical characterisation of the plasma source has also been carried out. 
Table 1 Summary of the pesticides studied in this work.

\begin{tabular}{|c|c|c|c|c|}
\hline Pesticide & Class & Chemical structure & Mode of action & MRL† \\
\hline $\begin{array}{l}\text { Azoxystrobin } \\
\text { Methyl (2E)-2-(2-[[6- } \\
\text { (2- } \\
\text { cyanophenoxy)pyrim } \\
\text { idin-4- } \\
\text { yl]oxy]phenyl)-3- }\end{array}$ & Fungicide & & $\begin{array}{l}\text { Binds with the } Q_{0} \text { site of Complex } \\
\text { III of the mitochondrial electron } \\
\text { transport chain, thereby } \\
\text { ultimately preventing the } \\
\text { generation of ATP in fungi [17]. }\end{array}$ & $\begin{array}{l}10 \mathrm{ppm} \\
\text { (both EU } \\
\text { and USA) }\end{array}$ \\
\hline
\end{tabular}

methoxyacrylate

\begin{tabular}{llll}
\hline $\begin{array}{l}\text { Pyriproxyfen } \\
\text { 4-phenoxyphenyl }\end{array}$ & $\begin{array}{l}\text { A juvenile hormone analog; } \\
\text { overloads the hormonal system of } \\
\text { (RS)-2-(2- }\end{array}$ & $\begin{array}{l}\text { EU: } 0.05 \\
\text { the target insect, ultimately }\end{array}$ \\
pyridyloxy)propyl & affecting egg production, brood & 0.3 ppm \\
ether & care and other social interactions, \\
& and inhibiting growth [18]
\end{tabular}

Cyprodinil
$\begin{aligned} & \text { 4-cyclopropyl-6- } \\ & \text { methyl-N- } \\ & \text { phenylpyrimidin-2- } \\ & \text { amine }\end{aligned}$

† Reference: www.mrldatabase.com

\section{Experimental}

\subsection{Produce}

Fresh strawberries (Fragaria ananasa, var. Elsanta) were purchased from the local wholesale fruit market (Dublin, Ireland) and stored under refrigerated conditions for $\sim 1 \mathrm{~h}$ before carrying out the experiments. The strawberries were screened for the presence of pesticides and those selected were found to be absent for the studied pesticides.

\subsection{Chemicals}

Acetone ( $\geq 99.9 \%$ capillary GC-grade), Dichloromethane ( $\leq 0.0005 \%$ non-volatile matter), Petroleum Ether, Ethyl Acetate ( $\leq 0.0005 \%$ non-volatile matter) and Sodium Sulphate (anhydrous) were all obtained from Sigma-Aldrich, Ireland. Azoxystrobin, Cyprodinil, Fludioxonil and Pyriproxyfen standards were also obtained from Sigma-Aldrich, Ireland.

\subsection{Exposure of samples to pesticides}

A cocktail of all the four pesticide standards was prepared in ethyl acetate at 100 ppm concentration each. Initial quality control runs in our laboratory have shown that the selected pesticides do not react with each other. To ensure a homogeneous distribution of pesticides on the fruit surface, we adopted the method of immersion into the pesticide solution 
for $15 \mathrm{~s}$. The dipped pesticides were allowed to air-dry under dark, inside a laminar flow hood for $1 \mathrm{~h}$, followed by a second dip for 15 s and repeated drying.

2.4. Plasma treatment

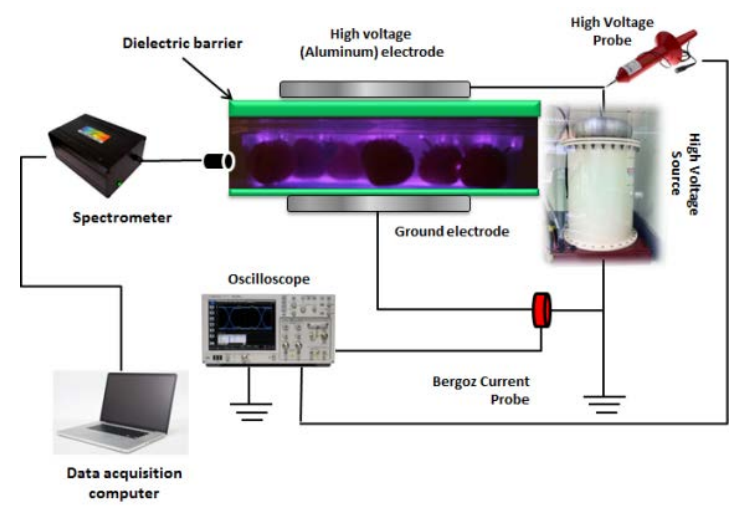

Figure 1 Schematic of the DBD experimental set-up for NTP treatments inside package. The package shown is filled with Helium for demonstration purpose.

A schematic of the experimental set-up employed in the study is presented in Figure 1. The DBD system comprises of two circular aluminium plate electrodes (outer diameter $=158 \mathrm{~mm}$ ) over dielectric layers $(10 \mathrm{~mm}$ thick perspex for high voltage electrode and $2 \mathrm{~mm}$ thick polypropylene for ground electrode) between which a PET (polyethylene terephthalate) package containing the food sample is placed. The high voltage step-up transformer (Phenix Technologies, Inc., USA) powered at $230 \mathrm{~V}, 50 \mathrm{~Hz}$ delivers a high voltage output in the range $0-120 \mathrm{kV} \mathrm{rms}$. Three discreet voltages viz. 60,70 and $80 \mathrm{kV}$ (RMS) at $50 \mathrm{~Hz}$ frequency were applied across the electrodes for these experiments. The rigid PET package had dimensions of $150 \mathrm{~mm} \times 150 \mathrm{~mm} \times 35 \mathrm{~mm}$ and also served as a dielectric material. Boxes with strawberry samples were sealed inside polymeric film of 50 micrometre thickness (Cryovac BB3050) with very low gas transmission rates, in order to prevent leakage of the plasma-generated reactive species. This film served as an additional layer of dielectric. All treatments were conducted in air. Literature reveals that most DBD treatments for food application operate in single diatomic gases or noble gases [6]. However, for practical applications, it is attractive to use less costly molecular gases, for example air [20]. The atmospheric air conditions at the time of packaging and treatment was $42 \pm 1 \%$ relative humidity $(\mathrm{RH})$ and $25 \pm 2{ }^{\circ} \mathrm{C}$, as measured using a humidity-temperature probe connected to a data logger (Testo $176 \mathrm{~T} 2$, Testo Ltd., UK). The strawberry samples were subjected to nonthermal plasma treatment for $60,120,180,240$, and 300 s and subsequently stored for 24 hour at $10{ }^{\circ} \mathrm{C}$ and $90 \% \mathrm{RH}$. These operating conditions were selected based on previous experiments conducted in our laboratory.

\subsection{Electrical measurements}

The voltage applied across the electrodes was monitored in the time domain using a high voltage probe (North Star PVM-6) coupled to a voltage divider to allow recording of the full voltage waveforms on an Agilent InfiniVision $2000 \mathrm{X}$-Series Oscilloscope (Agilent Technologies Inc., USA). A current transformer probe (Bergoz CT-E1.OS) was used to record the current waveforms.

\subsection{Ozone measurement}

Ozone concentrations within the package were measured immediately following plasma treatments (for the maximum treatment times only), using Gastec ozone detection tubes (Product No. 18M, Gastec, Japan). These tubes contain a chemical reagent, which changes colour after reaction with the specified gas. $10 \mathrm{~mL}$ of the gas was pulled out of the package, into the tube, using a gas sampling pump (Gastec, Japan) with a hypodermic needle. To avoid leakage of the gas, a silicone septum with adhesive was used at the point of gas sampling.

\subsection{Optical Emission spectroscopy}


The optical emission spectroscopy of the nonthermal plasma discharge was carried out using a Stellarnet EPP 2000C25 spectrometer at a resolution of $1.5 \mathrm{~nm}$. The light from the nonthermal plasma was coupled via an optical fibre. The diffraction grating in the spectrometer had a radius of curvature of $40 \mathrm{~mm}$ with 590 grooves per mm and an entrance slit width of $25 \mu \mathrm{m}$. The fibre had a numerical aperture of 0.22 and was optimised for performance in the ultraviolet and visible region of electromagnetic spectrum. The spectrometer operated in a wavelength window of $190 \mathrm{~nm}$ to $850 \mathrm{~nm}$. The integration time was $5000 \mathrm{~ms}$ and 5 samples were averaged for the collection of spectra. The emission spectra were qualitatively analysed to assign chemical species to the peaks. The spectra were noise cancelled, averaged and analysed using National Institute of Standards and Technology [21] atomic spectra database and published works [22, 23] for the identification of active chemical species.

\subsection{Analysis of pesticides}

\subsubsection{Extraction procedure}

A number of methods currently exist for the extraction and analysis of multi-residue pesticides from a variety of food matrices [24]. We employed the mini-Luke (multi-residue) method using acetone, dichloromethane and petroleum ether mixture (1:1:1) for the extraction of pesticide residues. Briefly, ca. $15 \mathrm{~g}$ of homogenised strawberry sample was blended (T25 Ultra-Turrax, Ika Works Inc., USA) with $30 \pm 1 \mathrm{~mL}$ of acetone, followed by addition of $30 \pm 1 \mathrm{~mL}$ of Dichloromethane and $30 \pm 1 \mathrm{~mL}$ of Petroleum ether and further blending. $30 \pm 1 \mathrm{~g}$ of sodium sulphate $\left(\mathrm{Na}_{2} \mathrm{SO}_{4}\right)$ was then added and blended for $30 \mathrm{~s}$ to salt out the polar pesticides. This mixture was then centrifuged for $5 \mathrm{~min}$ at $3500 \mathrm{rpm}$ and the organic phase collected. Subsequently $60 \mathrm{~mL}$ of the organic phase was concentrated in a rotary evaporator to ca. $2 \mathrm{~mL}$ with an intermediate step involving addition of $10 \mathrm{~mL}$ ethyl acetate. Appropriate dilutions were performed before loading on the auto sampler.

\subsubsection{GC-MS/MS Analysis}

Gas chromatography coupled to mass spectrometry (GC-MS/MS) is widely used in the analysis of pesticides that are highly volatile [25]. We employed an Agilent 7890N GC coupled with Agilent 7000A triple quadrupole MS for the analysis of pesticides, with ionization achieved by electron impact at $70 \mathrm{eV}$ in multiple reaction monitoring (MRM) mode. The capillary column used was an Agilent 190915-433 capillary column (30 m $\times 0.25$ mm I.D. $\times 0.25 \mu \mathrm{m}$ thickness) with HP-5MSI (5\% Phenyl Methylpolysiloxane) stationary phase. The operating conditions were: injection port temperature, $250^{\circ} \mathrm{C}$; interface temperature, $280^{\circ} \mathrm{C}$; column oven temperature, $100^{\circ} \mathrm{C}$ for $5 \mathrm{~min}$, ramped at $20^{\circ} \mathrm{C} / \mathrm{min}$ to $180^{\circ} \mathrm{C}$, followed by $5^{\circ} \mathrm{C} / \mathrm{min}$ to 280 ${ }^{\circ} \mathrm{C}$ for $10 \mathrm{~min}$; helium carrier gas (flow rate of $1.0 \mathrm{~mL} / \mathrm{min}$ ); $2 \mu \mathrm{L}$ injection volume. The split/splitless injector was operated in the split-less mode. Sample injection was automated with the use of an Agilent 7693 auto sampler.

\subsubsection{Calibration Curve}

A five point calibration curve was constructed for each fungicide covering a range of $10-250.0 \mathrm{ng} / \mathrm{mL}$. The resulting correlation coefficients were higher than 0.991 in all cases. Quantifications of pesticides based on peak area data were conducted using these curves.

\subsection{Data Analysis}

GC-MS data were acquired with Agilent MassHunter Workstation acquisition software and analysed using Agilent MassHunter Workstation Qual software (MassHunter Workstation, ver. B.05.000 SP02/Build 5.0.291.4, Agilent Technologies). The significance of differences among treatments was evaluated using Tukey multiple comparison test at significance levels of $\mathrm{p} \leq 0.05$ (SPSS ver 19, SPSS Inc., Chicago, IL).

The pesticide degradation data was fitted to pseudo-first order kinetics model using nonlinear least squares regression with Levenberg-Marquardt algorithm available from MATLAB 7.5 (The MathWorks, MA, USA). The first-order kinetics is given by

$$
C=C_{0} \exp (-k t)
$$


where, $C$ is the concentration of pesticide, $C_{0}$ the initial concentration of the pesticide, $k$ is the rate constant (1/s) of the reaction and $t$ is the time (s). The model fitting was evaluated based on the coefficient of regression $\left[R^{2}(\operatorname{adj})\right]$.

\section{Results and Discussion}

3.1. Current-Voltage characteristic of plasma source

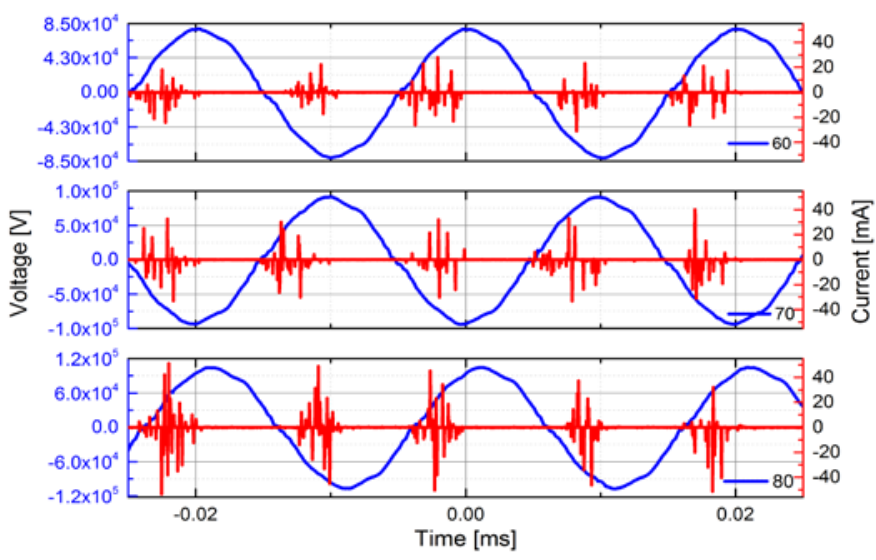

Figure 2 The current-voltage characteristics of the discharge in package with strawberries.

The representative waveforms for the three voltages are shown in Figure 2, where the applied voltage is sinusoidal, and the total current comprises of the displacement current superposed by numerous current pulses per half-cycle of the applied voltage. The discharge in the air can be characterised as operating in a typical filamentary regime with a microdischarge zone in each half-cycle of the applied voltage, which is organized by numerous streamer clusters at different durations up to the maximum of the applied voltage. The use of very high voltages favours generation of stable nonthermal plasma discharge even at wider gaps of $4 \mathrm{~cm}$. The dielectric material acts as a charge trapping agent [26], thereby limiting the charge transported and preventing the transition to an arc regime [27]. Further details regarding electrical characteristics of the discharge using capacitance-voltage Lissajous patterns can be found in a recent publication by our group [13].

\subsection{Ozone Concentration}

The dielectric barrier discharge phenomenon generates energetic electrons, which dissociate oxygen molecules by direct impact. The resulting singlet oxygen $\left(\mathrm{O}^{\circ}\right)$ combines with oxygen molecule $\left(\mathrm{O}_{2}\right)$ via a three body interaction to form ozone $\left(\mathrm{O}_{3}\right)$ as depicted in the following equations.

$$
\begin{aligned}
& e+O_{2} \rightarrow O+O+e \\
& O+O_{2}+M \rightarrow O_{3}+O_{2}\left(\text { where } M=O_{3} \text { or } O_{2}\right)
\end{aligned}
$$

The ozone concentrations measured after $300 \mathrm{~s}$ of plasma treatment were found to be 900,3100 and $3800 \mathrm{ppm}$ (within $\pm 10 \%$ error) for applied bias voltages of 60 , 70, and $80 \mathrm{kV}$ (RMS) respectively. Ozone is one of the most chemically stable and active species generated in DBD because of its relatively long lifetime and high oxidation potential [11].

\subsection{Optical Emission Spectroscopy (OES) of plasma}

A fraction of the energy delivered to the nonthermal plasma causes excitement of several chemical species to higher energy states, which are detectable from the emission spectra. In OES, the spectrum of the radiation emitted by the plasma is grated and the intensity is measured as function of the wavelength. Emission spectrum (in arbitrary units) of the filamentary discharge in an empty package and package with produce, for discharge at $80 \mathrm{kV}$ and 180 to $900 \mathrm{~nm}$ wavelength is presented in Figure 3. The spectral recording was begun within first few seconds of plasma discharge initiation. The 
emissions were stronger in the absence of any samples within the package. This is most likely an outcome of the limited gas

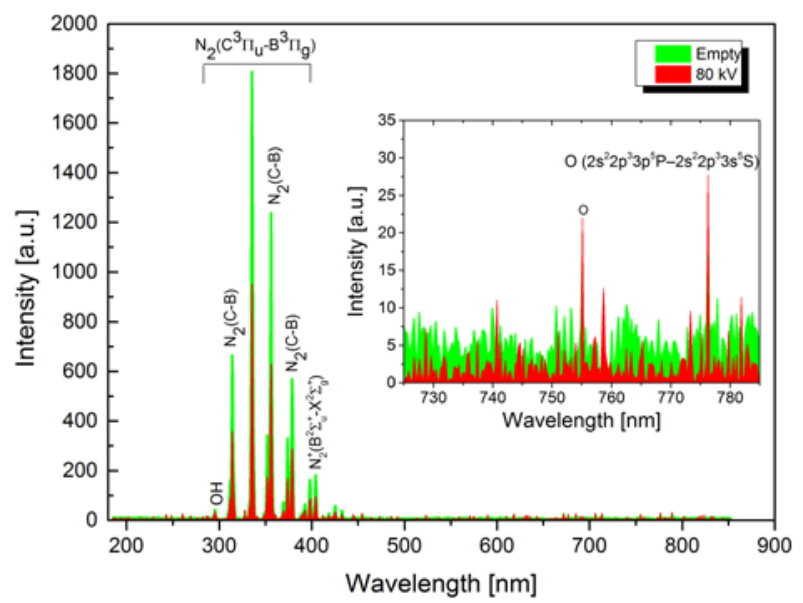
volume available in presence of the strawberries in addition to the solubilisation of the species into the moisture on the produce surface. The spectra exhibited identical peaks for other voltages with relatively less intensity of the major peaks, than at $80 \mathrm{kV}$ (data not shown).

Figure 3 Emission spectrum of the nonthermal plasma discharge (80 kV for $300 \mathrm{~s})$ in an empty package and package containing strawberries. Inset: zoom of the spectra around $750 \mathrm{~nm}$ showing less intense peaks from oxygen.

The emission spectrum clearly reveals emission in the near UV region (300-400 nm). DBDs operating at atmospheric pressures in air, in general, are weak source of UV [28]. Majority of the peaks obtained in the near UV region corresponded to intense emissions from $\mathrm{N}_{2}(\mathrm{C}-\mathrm{B})$ second positive system and $\mathrm{N}_{2}^{+}(\mathrm{B}-\mathrm{X})$ first negative system [29]. The small emission lines noted in the area 750 and $780 \mathrm{~nm}$ were attributed to $O$ atoms [22]. The relatively lower intensities of peaks associated with oxygen is due to quenching of $O\left({ }^{3} \mathrm{P}\right)$ and $O\left({ }^{5} \mathrm{P}\right)$ in the air plasma, as has been explained by Walsh, Liu, Iza, Rong and Kong [20]. The $\mathrm{OH}$ peak around $300 \mathrm{~nm}$ was also noticeable. These results point to the fact that the nonthermal plasma source was a source of reactive oxygen species (ROS) and excited nitrogen species (RNS). The gas phase chemistry of nonthermal discharges in air is complex and may involve as many as 500 reactions and 75 species [30-32]. Furthermore, complexity is also added by the wide ranges of length and time scales of such plasmas [33].

3.4. Quantification of pesticide residues and degradation kinetics

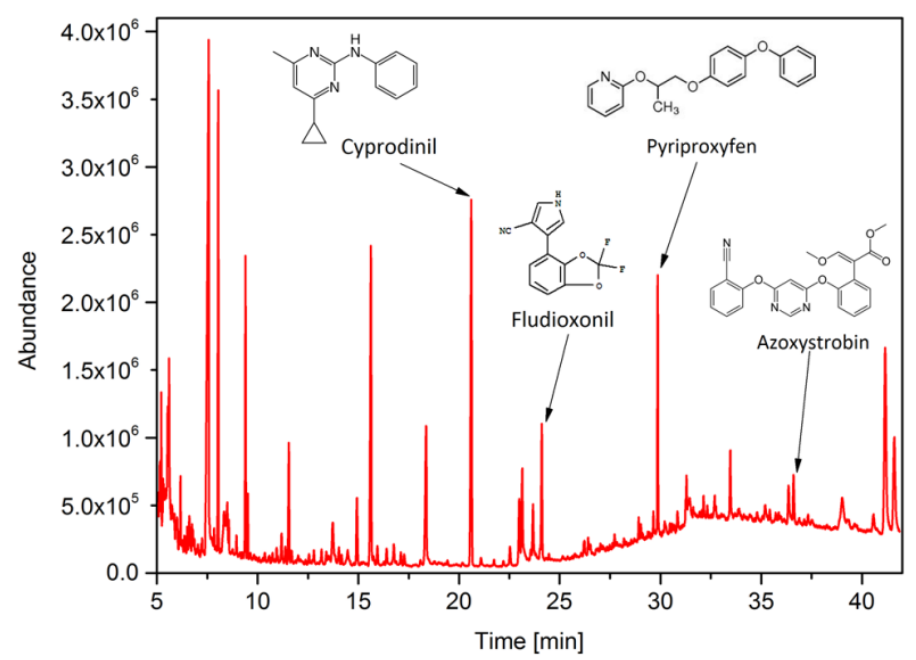

Figure 4 A representative chromatogram showing retention times of the four pesticides.

The four pesticides, namely azoxystrobin, cyprodinil, fludioxonil and pyriproxyfen were identified at retention times of 36.6, 20.6, 24.1 and 29.8 minute respectively (see Figure 4). The concentrations of the pesticides in the control samples were found to be $1709.8 \pm 212.4 \mathrm{ppb}, 2721.2 \pm 213.0 \mathrm{ppb}, 2540.2 \pm 44.7 \mathrm{ppb}$, and $1569.7 \pm 186.7 \mathrm{ppb}$ for azoxystrobin, cyprodinil, fludioxonil and pyriproxyfen respectively. These values suggested the appropriateness of dipping method for introducing pesticide residues onto strawberries. Following nonthermal plasma treatments and $24 \mathrm{~h}$ post-storage, a time and voltage dependent degradation of all the four pesticides was observed (see Figure 5). The decrease in the concentrations of the pesticide residues relative to the control were significant $(p \leq 0.05)$ for all the samples. Both applied voltage and treatment time were significant $(p \leq 0.05$ ) as process parameters governing the degradation. A maximum decrease of $69 \%, 45 \%, 71 \%$ and 
$46 \%$ was observed for azoxystrobin, cyprodinil, fludioxonil, and pyriproxyfen respectively after 300 s of treatment at an applied voltage of $80 \mathrm{kV}$. Except pyriproxyfen, the final concentration of all other pesticides following plasma treatment was found to be below the permitted maximum residual limit (MRL) (see Table 1).
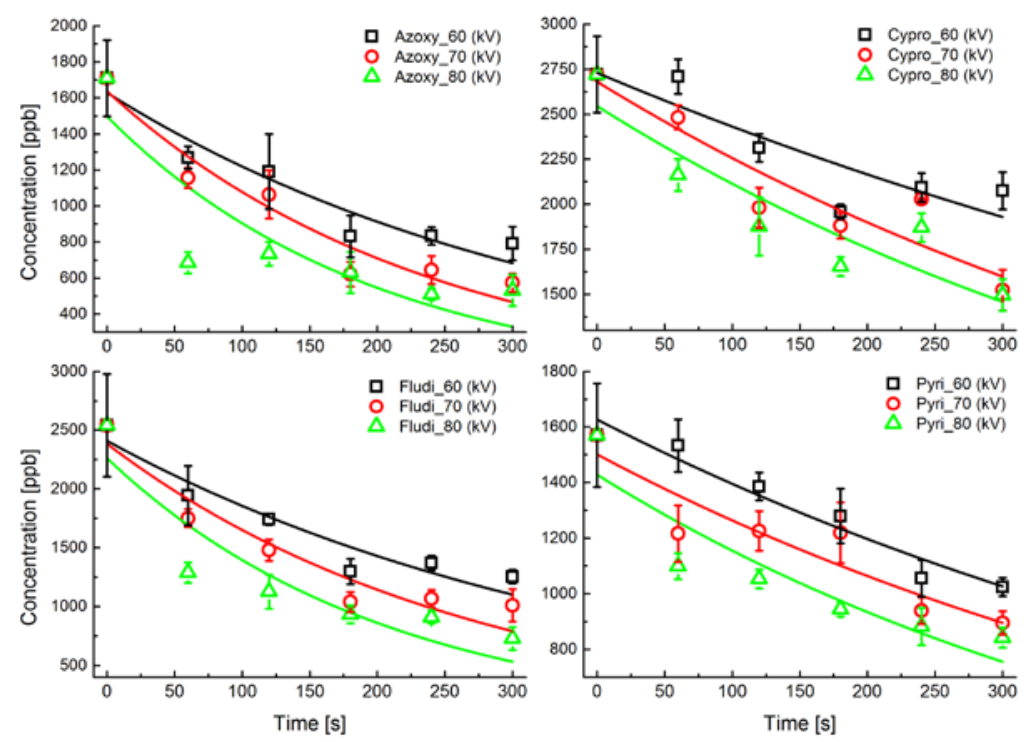

Figure 5 Residual pesticide concentrations in strawberries before and after plasma treatment.

Table 2 presents the first-order rate constant for the pesticide degradation under different voltages. Clearly, the rate constant $(k)$ increases with increase in voltage. It should be noted that the first-order rate kinetics is based on our assumption that ozone reacts with the pesticide to form the degraded product (c.f. [34]). The deviations from typical first-order kinetics of the degradation could be attributed to the geometric complexity of strawberries and the possible diffusion of the pesticides into the fruit interiors.

Table 2 Model parameters for pesticide degradation based on first-order kinetics

\begin{tabular}{llll}
\hline Pesticide & Voltage & Rate Constant, $\boldsymbol{k}\left(\boldsymbol{s}^{\mathbf{- 1}}\right)$ & $\boldsymbol{R}^{\mathbf{2}}$ (Adj.) \\
\hline Azoxystrobin & $60 \mathrm{kV}$ & $0.00290 \pm 4.97 \mathrm{E}-4$ & 0.76 \\
& $70 \mathrm{kV}$ & $0.00418 \pm 5.59 \mathrm{E}-4$ & 0.85 \\
& $80 \mathrm{kV}$ & $0.00505 \pm 0.00111$ & 0.65 \\
\hline Cyprodinil & $60 \mathrm{kV}$ & $0.00116 \pm 2.45 \mathrm{E}-4$ & 0.66 \\
& $70 \mathrm{kV}$ & $0.00172 \pm 2.77 \mathrm{E}-4$ & 0.78 \\
& $80 \mathrm{kV}$ & $0.00186 \pm 3.33 \mathrm{E}-4$ & 0.73 \\
\hline Fludioxonil & $60 \mathrm{kV}$ & $0.00261 \pm 4.86 \mathrm{E}-4$ & 0.72 \\
& $70 \mathrm{kV}$ & $0.00367 \pm 5.84 \mathrm{E}-4$ & 0.79 \\
& $80 \mathrm{kV}$ & $0.00482 \pm 9.14 \mathrm{E}-4$ & 0.74 \\
\hline Pyriproxyfen & $60 \mathrm{kV}$ & $0.00153 \pm 2.68 \mathrm{E}-4$ & 0.75 \\
& $70 \mathrm{kV}$ & $0.00172 \pm 3.58 \mathrm{E}-4$ & 0.68 \\
& $80 \mathrm{kV}$ & $0.00212 \pm 3.92 \mathrm{E}-4$ & 0.72
\end{tabular}

Degradation of pesticide residues on fruits by aqueous ozonation is already well established [35-37]. Recently, Karaca, Walse and Smilanick [38] demonstrated a decline of fenhexamid, cyprodinil, and pyrimethanil on table grapes, when stored in atmospheres of $0.3 \mu \mathrm{L} / \mathrm{L}$ ozone enriched air. Notably, very high ozone concentrations were detected immediately after plasma treatment in our experiments. By analogy, ozone can be considered as one of the active species responsible for the degradation of the pesticides, in addition to the other myriad of species generated by plasma. Ozone can also undergo reaction with water to yield peroxide and hydroxyl radicals. The degradation of cyprodinil is probably an outcome of the 
attack at the nitrogen bridge between the two rings or the phenyl ring and/or the pyrimidyl ring by hydroxyl radicals formed from ozone [39] as typified in Figure 6 and further oxidation by Criegee mechanism.

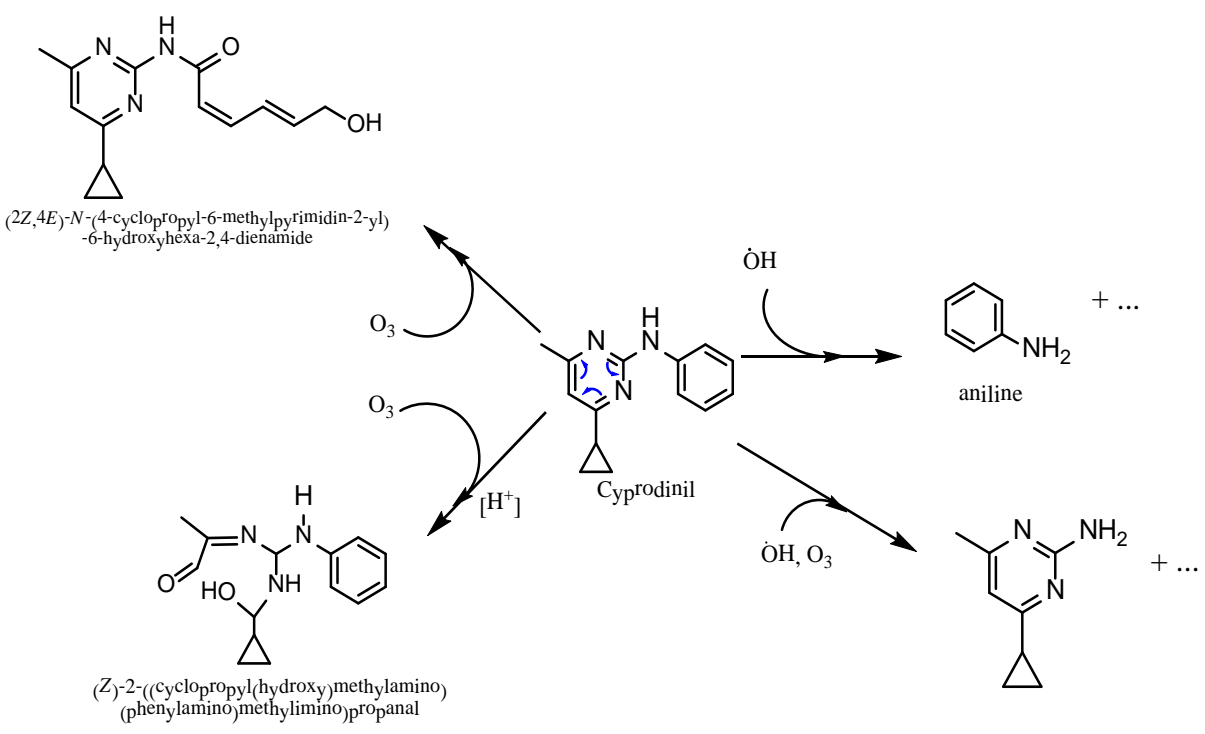

Figure 6 Proposed reaction products for Cyprodinil (based on [34]).

As a general observation, the degradation kinetics indicates that the rate of degradation (slope) decreases with increase in treatment time (note the logarithmic scale). This can be linked with the kinetics of air plasma chemistry where excited nitrogen species are favoured over oxygen species for extended time scales [40]. This type of exclusive competitive reaction mode has also been suggested for photo-induced degradation of diuron (herbicide) in aqueous solution by nitrites and nitrates with photolysis of water (which yields $\mathrm{OH}$ radicals) [41]. It may be noted that treatments for 240 and $300 \mathrm{~s}$ did not have significant effect on the degradation of azoxystrobin. Bai, Chen, Yang, Guo and Zhang [9] have reported similar observations, where the effect of an increase in applied power to plasma has insignificant effect on the degradation of dichlorovos. The excited nitrogen species despite their short life-time can shield the action of the ozone by forming local acidic environments, after the discharge is turned off. However, using optical absorption spectroscopy we have confirmed the presence of ozone in packages for up to 4-6 h even after the discharge is turned off [42]. The degradation of azoxystrobin in alkaline environments over acidic is already reported in the literature [43]. Since azoxystrobin has several functional groups, this most likely provides several sites for the attack by the active chemical species of NTP. It has been suggested that the photodegradation of azoxystrobin proceeds via multiple, parallel reaction pathways including photo-isomerization, photo-hydrolysis of the methyl ester and of the nitrile group, cleavage of the acrylate double bond, photohydrolytic ether cleavage between the aromatic ring resulting in phenol, and oxidative cleavage of the acrylate double bond [44, 45]. Similarly, the degradation of pyriproxyfen most likely begins by the cleavage of central ether linkage.

In order to explore the possible degradation mechanisms of pesticides, it is important to identify the intermediates and by-products during plasma treatment [9]. However, it is worthwhile noting that the identification and toxicity determination of the degradation products is often quite difficult, considering the number of breakdown products that could form after exposure to various treatments [38]. Unavailability of commercial standards of the degraded products also adds to the analytical problems. We also performed a total ion scan with an aim to identify the degradation reaction pathway. We found an unidentified peak at 6.51 min with abundance in $201 \mathrm{~m} / \mathrm{z}$ ion fragment. Based on previous reports [46], we propose the degradation pathway for fludioxinil shown in Figure 7, whose end product is assigned to the peak at 6.51 min. Besides this there could be other unidentified free or conjugated degradation products. We wish to highlight that it was difficult to make any conclusions or identify common degradation products reported in the literature for all other pesticides, with added complexities from the compounds of strawberry matrix. The large number of peaks observed in the chromatogram (Figure 4) corresponds to non-polar metabolites of strawberries. Therefore, at this point the identification of degradation products using NMR spectroscopy is planned as a future work. 

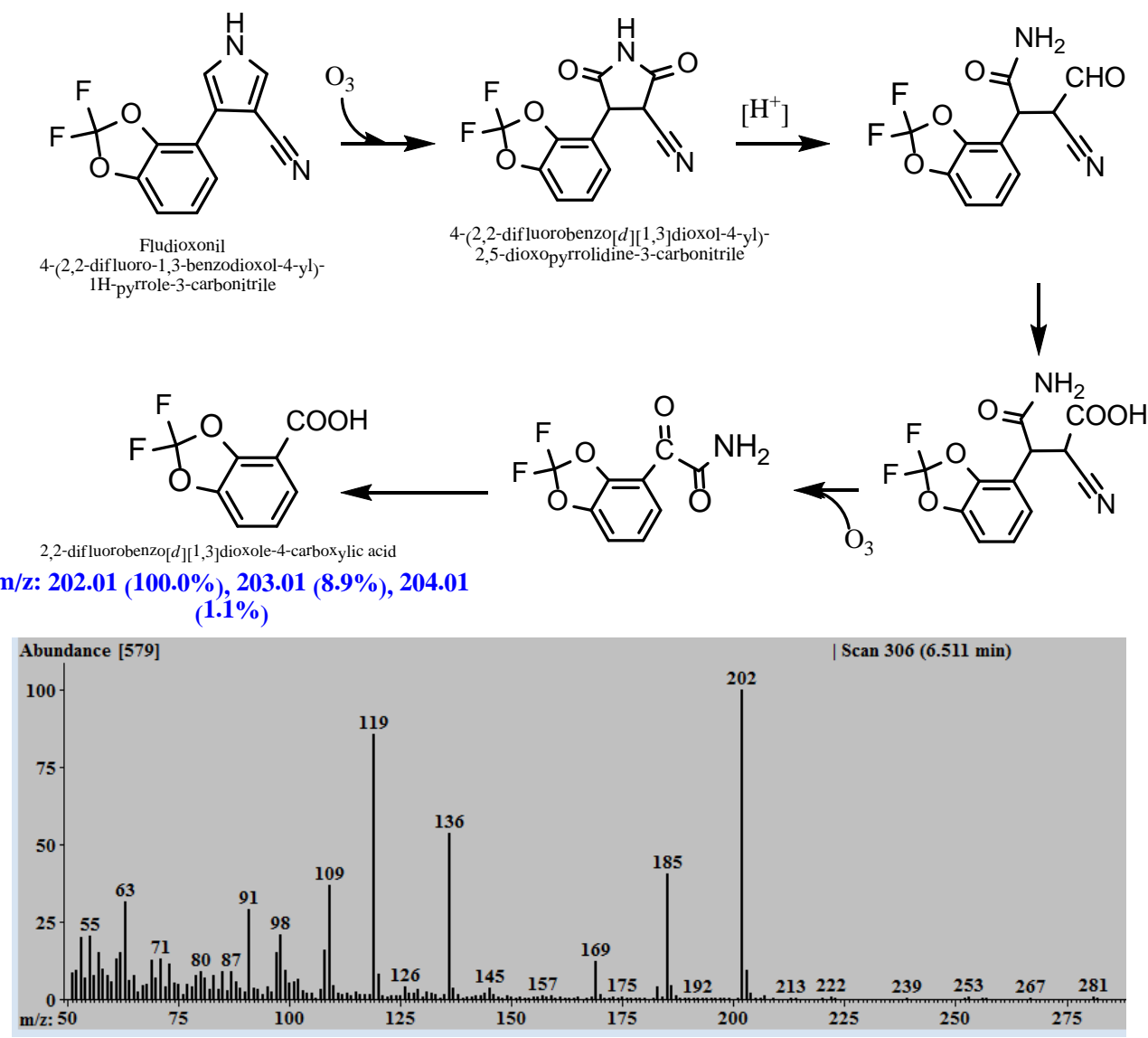

Figure 7 Proposed mechanisms for degradation of Fludioxonil (see c.f. [46]). On bottom is the mass spectrum of the peak obtained at 6.51 min which shows abundance in the $202 \mathrm{~m} / \mathrm{z}$ peak.

\section{Conclusions}

Nonthermal plasma treatment using a dielectric barrier discharge successfully degraded pesticide residues on strawberries. The discharge operating in the filamentary regime was found to be a source of reactive oxygen and excited nitrogen species, as observed using ozone detection tubes (chemically) and optical emission spectroscopy. In particular, the levels of azoxystrobin, cyprodinil, fludioxonil and pyriproxyfen decreased by a maximum of $69 \%, 45 \%, 71$ and $46 \%$ respectively after 5 minute of treatment at $80 \mathrm{kV}$ (RMS). The kinetics of degradation was modelled using a simple first-order differential rate equation. These findings suggest the potential of nonthermal plasma treatment as a means to ensure chemical food safety, in addition to its proven microbicidal effects. Future studies must focus on identifying the degradation products, and unravelling the mechanism of degradation(s) using advanced methods and model systems.

\section{Acknowledgements}

The authors would like to acknowledge funding from the Food Institutional Research Measure (Grant \# 13/F/442), administered by the Department of Agriculture, Food \& the Marine Ireland. Support from the Irish Research Council in the form of Embark fellowship to NN Misra is also gratefully acknowledged. 


\section{References}

[1] V.L. Garau, A. Angioni, A.A. Del Real, M. Russo, P. Cabras, Disappearance of azoxystrobin, pyrimethanil, cyprodinil, and fludioxonil on tomatoes in a greenhouse, Journal of Agricultural and Food Chemistry, 50 (2002) 1929-1932.

[2] T. lizuka, S. Maeda, A. Shimizu, Removal of Pesticide Residue in Cherry Tomato by Hydrostatic Pressure, Journal of Food Engineering, In Press (2013).

[3] Y. Yamaguchi, Environmental and Food Hygiene Approach to Pesticide, Journal of Urban Living and Health Association, 50 (2006) 283-290.

[4] M.A. Lieberman, A.J. Lichtenberg, Principles of plasma discharges and materials processing, Second ed., John Wiley and Sons, Inc., New York, 2005.

[5] P. Attri, B. Arora, E.H. Choi, Utility of plasma: a new road from physics to chemistry, RSC Advances, 3 (2013) 12540-12567.

[6] N.N. Misra, B.K. Tiwari, K.S.M.S. Raghavarao, P.J. Cullen, Nonthermal Plasma Inactivation of FoodBorne Pathogens, Food Engineering Reviews, 3 (2011) 159-170.

[7] B.A. Niemira, Cold Plasma Decontamination of Foods, Annual Review of Food Science and Technology, 3 (2012) 125-142.

[8] Y. Bai, J. Chen, H. Mu, C. Zhang, B. Li, Reduction of dichlorvos and omethoate residues by $\mathrm{O} 2$ plasma treatment, Journal of Agricultural and Food Chemistry, 57 (2009) 6238-6245.

[9] Y. Bai, J. Chen, Y. Yang, L. Guo, C. Zhang, Degradation of organophosphorus pesticide induced by oxygen plasma: effects of operating parameters and reaction mechanisms, Chemosphere, 81 (2010) 408-414.

[10] S.H. Kim, J.H. Kim, B.K. Kang, Decomposition reaction of organophosphorus nerve agents on solid surfaces with atmospheric radio frequency plasma generated gaseous species, Langmuir : the ACS journal of surfaces and colloids, 23 (2007) 8074-8078.

[11] N.N. Misra, D. Ziuzina, P.J. Cullen, K.M. Keener, Characterization of a novel atmospheric air cold plasma system for treatment of packaged biomaterials, Transactions of the ASABE, 56 (2013) 10111016.

[12] D. Ziuzina, S. Patil, P.J. Cullen, K.M. Keener, P. Bourke, Atmospheric cold plasma inactivation of Escherichia coli in liquid media inside a sealed package, Journal of applied microbiology, 114 (2013) 778-787.

[13] N.N. Misra, S. Patil, T. Moiseev, P. Bourke, J.P. Mosnier, K.M. Keener, P.J. Cullen, In-package atmospheric pressure cold plasma treatment of strawberries, Journal of Food Engineering, 125 (2014) 131-138.

[14] S.K. Pankaj, N.N. Misra, P.J. Cullen, Kinetics of tomato peroxidase inactivation by atmospheric pressure cold plasma based on dielectric barrier discharge, Innovative Food Science \& Emerging Technologies, 19 (2013) 153-157.

[15] S.K. Pankaj, C. Bueno-Ferrer, N.N. Misra, L. O’Neill, A. Jiménez, P. Bourke, P.J. Cullen, Characterization of polylactic acid films for food packaging as affected by dielectric barrier discharge atmospheric plasma, Innovative Food Science \& Emerging Technologies, in-press (2013).

[16] S.K. Pankaj, C. Bueno-Ferrer, N.N. Misra, V. Milosavljević, C.P. O'Donnell, P. Bourke, K.M. Keener, P.J. Cullen, Applications of cold plasma technology in food packaging, Trends in Food Science \& Technology, (2013).

[17] N. Singh, S.B. Singh, Effect of moisture and compost on fate of azoxystrobin in soils, Journal of environmental science and health. Part. B, Pesticides, food contaminants, and agricultural wastes, 45 (2010) 676-681.

[18] P. Masner, P. Muster, J. Schmid, Possible methionine biosynthesis inhibition by pyrimidinamine fungicides, Pesticide science, 42 (1994) 163-166.

[19] P. Cabras, A. Angioni, V.L. Garau, M. Melis, F.M. Pirisi, E.V. Minelli, F. Cabitza, M. Cubeddu, Fate of Some New Fungicides (Cyprodinil, Fludioxonil, Pyrimethanil, and Tebuconazole) from Vine to Wine, Journal of agricultural and food chemistry, 45 (1997) 2708-2710. 
[20] J.L. Walsh, D.X. Liu, F. Iza, M.Z. Rong, M.G. Kong, Contrasting characteristics of sub-microsecond pulsed atmospheric air and atmospheric pressure helium-oxygen glow discharges, Journal of Physics D: Applied Physics, 43 (2010) 032001.

[21] National Institute of Standards and Technology, Atomic spectra database, in, 2012.

[22] A. Meiners, Optical emission spectroscopy for plasma diagnostics- Application note, Andor Technologies, (2010).

[23] J. Connolly, V.P. Valdramidis, E. Byrne, K.A. Karatzas, P.J. Cullen, K.M. Keener, J.P. Mosnier, Characterization and antimicrobial efficacy against E. coli of a helium/air plasma at atmospheric pressure created in a plastic package, Journal of Physics D-Applied Physics, 46 (2013) 035401.

[24] R. Đurović, T. Đorđević, Modern Extraction Techniques for Pesticide Residues Determination in Plant and Soil Samples, in: M. Stoytcheva (Ed.) Pesticides in the Modern World - Trends in Pesticides Analysis, InTech Open, 2011.

[25] D.T. Likas, N.G. Tsiropoulos, G.E. Miliadis, Rapid gas chromatographic method for the determination of famoxadone, trifloxystrobin and fenhexamid residues in tomato, grape and wine samples, Journal of chromatography. A, 1150 (2007) 208-214.

[26] A.S. Chiper, G. Popa, Temporally, spatially, and spectrally resolved barrier discharge produced in trapped helium gas at atmospheric pressure, Journal of Applied Physics, 113 (2013) 213302.

[27] B.P. Dojcinovic, G.M. Roglic, B.M. Obradovic, M.M. Kuraica, M.M. Kostic, J. Nesic, D.D. Manojlovic, Decolorization of reactive textile dyes using water falling film dielectric barrier discharge, Journal of Hazardous Materials, 192 (2011) 763-771.

[28] M. Heise, T. Lierfeld, O. Franken, W. Neff, Single filament charge transfer and UV-emission properties of a cascaded dielectric barrier discharge (CDBD) set-up, Plasma Sources Science and Technology, 13 (2004) 351.

[29] A. Gaydon, R. Pearse, The identification of molecular spectra, Chapman and Hall, London, 1976.

[30] F.J. Gordillo-Vázquez, Air plasma kinetics under the influence of sprites, Journal of Physics D: Applied Physics, 41 (2008) 234016.

[31] J.T. Herron, D.S. Green, Chemical kinetics database and predictive schemes for nonthermal humid air plasma chemistry. Part II. Neutral species reactions, Plasma Chemistry and Plasma Processing, 21 (2001) 459-481.

[32] L.W. Sieck, J.T. Heron, D.S. Green, Chemical Kinetics Database and Predictive Schemes for Humid Air Plasma Chemistry. Part I: Positive Ion-Molecule Reactions, Plasma Chemistry and Plasma Processing, 20 (2000) 235-258.

[33] W. Park, E.V. Belova, G.Y. Fu, X.Z. Tang, H.R. Strauss, L.E. Sugiyama, Plasma simulation studies using multilevel physics models, Physics of Plasmas, 6 (1999) 1796.

[34] S.S. Walse, H. Karaca, Remediation of Fungicide Residues on Fresh Produce by Use of Gaseous Ozone, Environmental Science \& Technology, 45 (2011) 6961-6969.

[35] G. Reynolds, N. Graham, R. Perry, R.G. Rice, Aqueous Ozonation of Pesticides: A Review, Ozone: Science \& Engineering, 11 (1989) 339-382.

[36] K.C. Ong, J.N. Cash, M.J. Zabik, M. Siddiq, A.L. Jones, Chlorine and ozone washes for pesticide removal from apples and processed apple sauce, Food Chemistry, 55 (1996) 153-160.

[37] E.-S. Hwang, J.N. Cash, M.J. Zabik, Postharvest Treatments for the Reduction of Mancozeb in Fresh Apples, Journal of agricultural and food chemistry, 49 (2001) 3127-3132.

[38] H. Karaca, S.S. Walse, J.L. Smilanick, Effect of continuous $0.3 \mu \mathrm{L} / \mathrm{L}$ gaseous ozone exposure on fungicide residues on table grape berries, Postharvest Biology and Technology, 64 (2012) 154-159. [39] L. Anfossi, P. Sales, A. Vanni, Degradation of anilinopyrimidine fungicides photoinduced by iron(III)-polycarboxylate complexes, Pest management science, 62 (2006) 872-879.

[40] I.A. Kossyi, A.Y. Kostinsky, A.A. Matveyev, V.P. Silakov, Kinetic scheme of the non-equilibrium discharge in nitrogen-oxygen mixtures, Plasma Sources Science and Technology, 1 (1992) 207.

[41] M.V. Shankar, S. Nelieu, L. Kerhoas, J. Einhorn, Photo-induced degradation of diuron in aqueous solution by nitrites and nitrates: kinetics and pathways, Chemosphere, 66 (2007) 767-774. 
[42] T. Moiseev, N.N. Misra, P. Bourke, P.J. Cullen, J.P. Mosnier, Non-thermal DBD plasma for in-pack sterilization: diagnostics on SAFE-BAG using electrical and optical methods, in: 11th UK Technological Plasma Workshop (TPW), The University of York, York Plasma Institute, UK, 2013. [43] N. Singh, S.B. Singh, I. Mukerjee, S. Gupta, V.T. Gajbhiye, P.K. Sharma, M. Goel, P. Dureja, Metabolism of 14C-azoxystrobin in water at different $\mathrm{pH}$, Journal of environmental science and health. Part. B, Pesticides, food contaminants, and agricultural wastes, 45 (2010) 123-127.

[44] E.T. Rodrigues, I. Lopes, M.A. Pardal, Occurrence, fate and effects of azoxystrobin in aquatic ecosystems: a review, Environment international, 53 (2013) 18-28.

[45] A. Boudina, C. Emmelin, A. Baaliouamer, O. Paisse, J.M. Chovelon, Photochemical transformation of azoxystrobin in aqueous solutions, Chemosphere, 68 (2007) 1280-1288.

[46] T.R. Roberts, D.H. Hutson, Fludioxonil, in: Metabolic Pathways of Agrochemicals: Insecticides and fungicides, Royal Society of Chemistry, Cambridge, UK, 1999, pp. 1295-1298. 